\title{
Keratoconus Screening in Primary Eye Care - A General Overview
}

\author{
Sara Ortiz-Toquero', and Raul Martin ${ }^{1,2,3}$ \\ 1. Optometry Research Group, IOBA Eye Institute, School of Optometry, University of Valladolid, Valladolid, Spain; 2. Universidad de Valladolid, \\ Departamento de Física Teórica, Atómica y Óptica, Valladolid, Spain; 3. School of Health Professions, Plymouth University, Plymouth, UK
}

$\mathrm{K}$ eratoconus early detection (screening) and diagnosis requires an in-deep corneal analysis with different techniques; slip lamp assessment, corneal topography and corneal tomography are the most commonly accepted to detect clinical signs and assess anterior and posterior corneal surface and global corneal pachymetry. However, keratoconus early detection and definitive diagnosis are two different clinical procedures that require a different approach and goals. The aim of this review is to provide some general information about different corneal assessment technology, useful in keratoconus patient assessment; highlighting the differences in the adequate investigation techniques to its detection in primary eye care clinic and to conduct the definitive diagnosis (usually in a cornea specialist clinic). Information of most extensively available commercial devices and the advantages and disadvantages of their use in keratoconus early detection and diagnosis are described. In conclusion, corneal topography (Placido-based keratographers) plays a significant role in keratoconus detection, especially in primary eye care clinics. However, corneal tomography (with different slit scanning and/or rotational imaging devices) including posterior corneal surface assessment and global corneal pachymetry investigation, is critical in definitive keratoconus diagnosis.

\section{Keywords}

Keratoconus, early detection, screening, corneal topography, corneal tomography, primary eye care

Disclosure: Sara Ortiz-Toquero was supported by Junta Castilla y León (Consejeria de Educación), Program, Estrategia Regional de Investigación Científica, Desarrollo Tecnológico e Innovación 2007-2013, co-funding by Social European Fund. Raul Martin has nothing to disclose is relation to this article. No funding has been received for the publication of this article. This study involves a review of the literature and did not involve any studies with human or animal subjects performed by any of the authors.

Acknowledgements: The authors would like to thank Mr Gonzalo Velarde Rodriguez, (Clinilaser, Madrid, Spain), Dr Victoria de Juan (Hospital Ramon y Cajal, Madrid, Spain) and Mrs Guadalupe Rodriguez Zarzuelo (IOBA Eye Institute, University of Valladolid, Valladolid, Spain) for their collaboration in this manuscript preparation.

Authorship: All named authors meet the International Committee of Medical Journal Editors (ICMJE) criteria for authorship of this manuscript, take responsibility for the integrity of the work as a whole, and have given final approval to the version to be published.

open Access: This article is published under the Creative Commons Attribution Noncommercial License which permits any non-commercial use, distribution, adaptation and reproduction provided the original author(s) and source are given appropriate credit.

Received: 28 September 2016

Accepted: 11 Novermber 2016

Citation: European Ophthalmic Review,

2016;10(2):80-5

Corresponding Author: Raul Martin, IOBA Eye Institute, University of Valladolid, Campus Miguel Delibes, 47011 Valladolid, Spain. Faculty of Health and Human Sciences, Plymouth University, Derriford Road, Plymouth, PL6 8BH, UK; E: raul@ioba.med.uva.es
Keratoconus early detection (screening) and diagnosis requires an in-deep corneal analysis with different techniques available. ${ }^{1}$ Slip lamp assessment and corneal topography/tomography are the most commonly accepted techniques in eye examination.

Corneal topography and corneal tomography are useful terms that distinguish between two different types of corneal examination, so both will coexist and be complementary. ${ }^{2}$ In fact, hybrid systems, combining Placido disk-based videokeratography and slit-scan images provide reliable corneal measurements in keratoconus assessment. ${ }^{3,4}$

The aim of this review is to provide general information about different corneal assessment technologies useful in keratoconus assessment; highlighting the different investigative techniques from its detection in the primary eye care clinic to definitive diagnosis, usually in the cornea specialist clinic. Information of most extensively available commercial devices, and the advantages and disadvantages of their use in keratoconus early detection and diagnosis, are described.

\section{Method of literature search}

We performed an extensive electronic search of the Medline and PubMed databases using individual and combinations of key words (keratoconus, keratoconus fustre, subclinical keratoconus, keratoconus treatment, keratoconus topography, keratoconus tomography, scheimpflug, keratoconus biomechanical properties and keratoconus anterior OCT) in May 2016 to identify the relevant publications in this field. We included the references if they focused on assessment techniques of the cornea in keratoconus patients. We excluded techniques that are considered experimental, non-English publications and case reports.

\section{Keratoconus}

Keratoconus is a multifactorial disease with genetic, biochemical, biomechanical, and environmental pathophysiology, ${ }^{5}$ characterised by a thinning and steepening of the central and paracentral cornea, affecting approximately $1 / 2000$ people in the general population. ${ }^{6-8}$ Commonly, this bilateral and asymmetric ectatic condition appears during the second decade of life and puberty and it progresses until the fourth decade of life, causing high myopia and irregular astigmatism..$^{5-8}$ Keratoconus patient management requires a multi-professional approach for early detection, correct diagnosis, follow up, monitoring and adequate management that involve: primary eye care practitioners, optometrists, contact lens (CL) practitioners and ophthalmologists with the last aim to provide better care and improve patients' quality of life..$^{9,10}$ 
Keratoconus detection, diagnosis and classification Keratoconus diagnosis is a challenge. ${ }^{5,7}$ Early stages of keratoconus, where clinical signs are not manifest on biomicroscopy (stromal thinning, conical protrusion, Fleischer corneal epithelial iron ring, Munson sign, Rizzuti sign or Vogt striae) ${ }^{7.8}$ but the cornea demonstrates subtle topographic features comparable to those of clinical keratoconus receive the name of fruste keratoconus, subclinical keratoconus or keratoconus suspect.,11-13 Therefore, distinguishing between healthy cornea and early keratoconus (in opposition to moderate or advanced stages), of subclinical keratoconus or other ectatic diseases imposes greater diagnostic challenge. ${ }^{5,7}$ It is of paramount clinical importance in primary eye care and in screening refractive surgical patients to avoid iatrogenic corneal ectasia after laser surgery. ${ }^{14-16}$

Clinical keratoconus is reliably detected with Placido disk-based corneal topography and even sometimes at slit-lamp examination. ${ }^{16}$ Other technologies, such as: corneal tomography (Scheimpflug or dual Scheimpflug devices), ${ }^{3,1,1,17}$ anterior segment optical coherence tomography (AS-OCT), ${ }^{18,19}$ biomechanical devices ${ }^{20,21}$ that analyse the anterior and posterior corneal surface, full corneal thickness map, epithelial mapping, or corneal biomechanical properties are necessary to complete keratoconus diagnosis. ${ }^{5,22}$

Currently, there is no clinically accepted classification allowing eyecare practitioners to clearly differentiate between healthy and keratoconus cornea (especially in early stages), and that could be used in patients' follow-up in suspect (or diagnosed) cases. The most common classifications were the Amsler-Krumeich, ${ }^{23}$ and Collaborative Longitudinal Evaluation of Keratoconus (CLEK) ${ }^{24}$ Classifications. However, both classifications fail to address current information and technological advances 5 and a new classification criterion is necessary.

The Amsler-Krumeich classification proposes four different stages using refractive, topographic and biomicroscopic corneal signs. The CLEK classification proposes to use the average corneal power and root mean square (RMS) error for higher-order Zernike terms (derived from the first corneal surface wavefront) combined with clinical biomicroscopic signs. Because larger values of vertical coma have been found in keratoconic corneas, high-order corneal aberration analysis could play a relevant role in future keratoconus classification ${ }^{24-28}$ Therefore, future keratoconus classifications will be directly dependent on the accuracy and reliability of the corneal device used in patient assessment. ${ }^{27,29}$

\section{Corneal topography}

corneal topography is a method of computer-assisted, non-invasive examination of the anterior surface of the cornea. It provides a qualitative and quantitative description of the morphology of the cornea in a topographical map after analysing the reflected image of illuminated rings (Placido disk) onto the corneal surface (Figure 1). ${ }^{30}$

Corneal topography was introduced in the mid-1980s with the developing of different algorithms to analyse the Placido photokeratoscope's images, and has represented a true revolution in the diagnosis and management of corneal disease, ${ }^{2}$ including keratoconus. Nowadays, corneal topographers are one of the most extensively used devices in clinical practice. ${ }^{26,29}$

In fact, several mathematical indices have been developed with the aim of helping with keratoconus detection, grading the disease and monitoring its progression. ${ }^{26,31}$ For example; central keratometry (K-value) ${ }^{32}$ with

\section{Figure 1: Placido-based topography in a keratoconus patient}

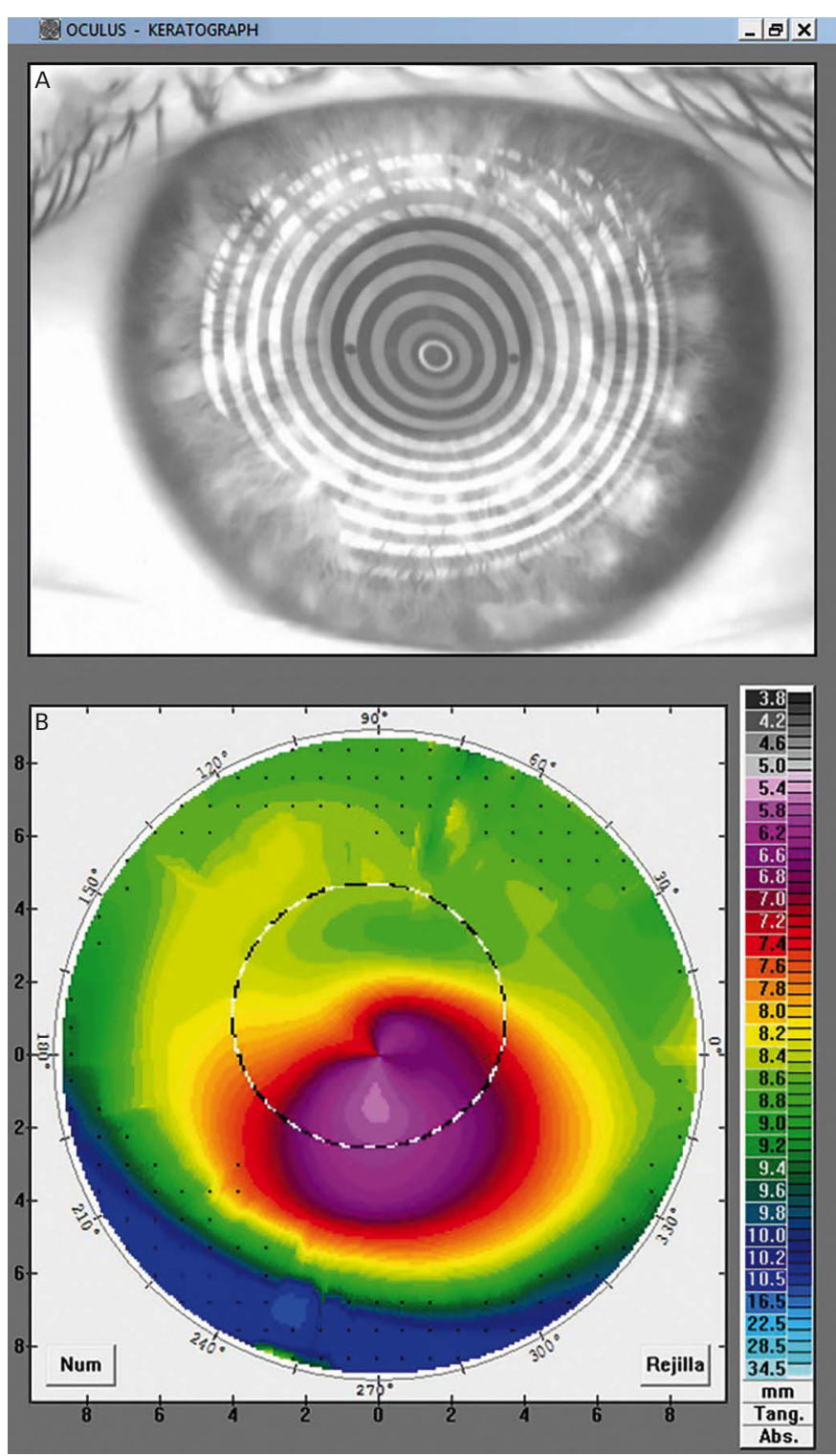

A. Placido image; B. Tangential (power) map. Keratograph (OCULUS, Optikgeräte GmbH Wetzlar, Germany).

different cut-off values to keratoconus suspect (>47.2 D); inferiorsuperior asymmetry (I-S value $)^{32}$ with a cut-off value of $1.4 \mathrm{D}$ difference between average inferior and superior corneal powers at $3 \mathrm{~mm}$ from the centre of the cornea; the steepest radial axes (SRAX) (2) $^{32}$ calculated with the angle between the steepest superior meridian and steepest inferior meridian; surface asymmetry index (SAl) $)^{33,34}$; keratoconus severity score $(\text { KSS })^{24}$ calculated with some corneal topography features (axial pattern, average corneal power and higher-order RMS) and slit-lamp signs (including scarring); keratoconus prediction index (KPI) ${ }^{35}$ calculated after a discriminant analysis of eight quantitative videokeratography indices (Simulated K1, Simulated K2, opposite sector index [OSI], centre/surround index [CSI], differential sector index [DSI], SAI, irregular astigmatism index $[\mathrm{IAI}]$ and analysed area [AA]); keratoconus percentage index (KISA\%) ${ }^{36}$ based on K-value, I-S value, keratometric astigmatism (AST), and SRAX indices; or cone location and magnitude index (CLMI), ${ }^{37}$ calculated with the axial and tangential curvature data.

However, most of these indices depend on the topography software, but with sensitivity and specificity controversial, they may be difficult to understand ${ }^{38}$ and have not been extensively used in clinical practice. 
Figure 2: Corneal tomography in a keratoconus patient

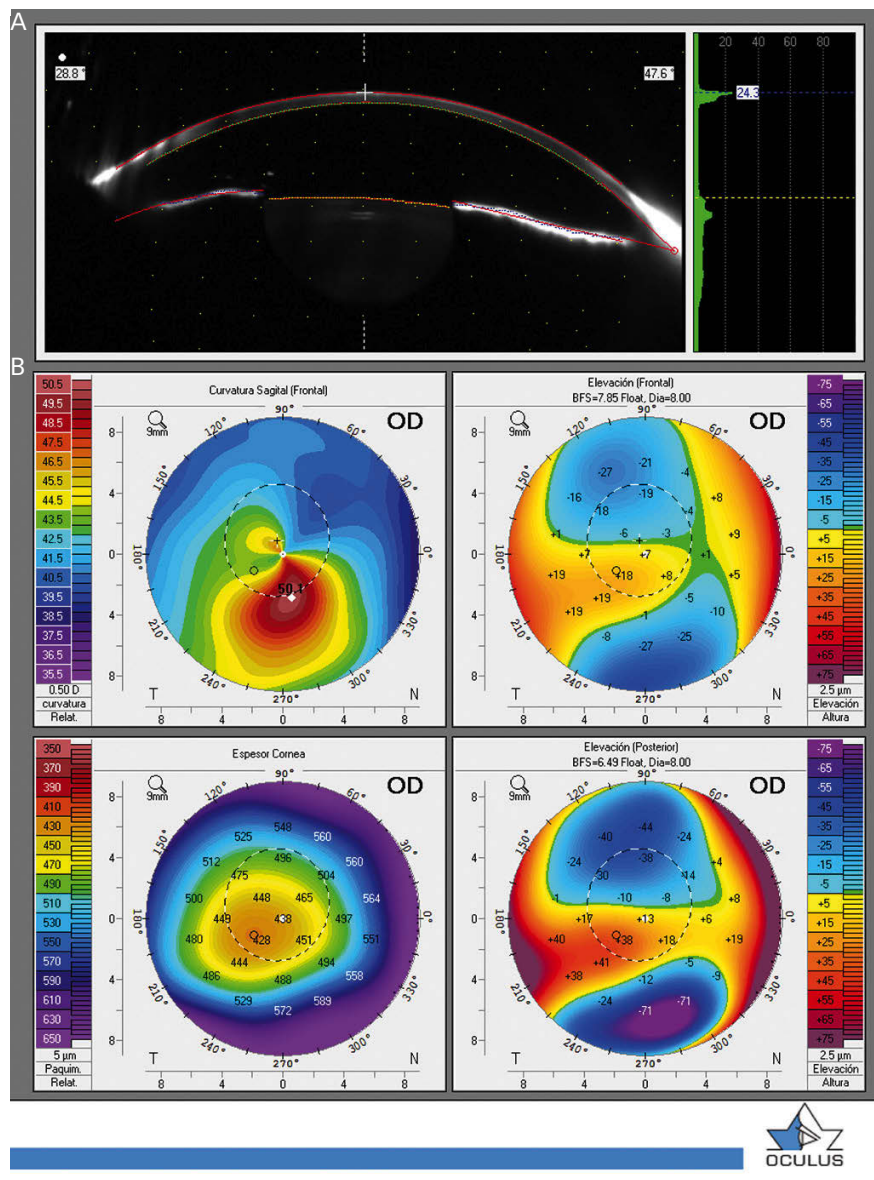

A. Scan image (Scheimpflug image); B. Axial (power) map, anterior and posterior elevation maps, and global pachymetry map. Pentacam (OCULUS Optikgeräte GmbH, Wetzlar, Germany).

Therefore, new criteria, easy to use and non-device dependent methods would be necessary to improve keratoconus detection, diagnosis and classification. ${ }^{27,29}$

Gas permeable (GP) CL fitting is the primary keratoconus management option. ${ }^{6-8,39}$ However, fitting of GP lenses in keratoconus patients is challenging because the irregular cornea often requires several diagnostic lenses to achieve a final acceptable GP lens fit, which prolongs practitioner and patient chair time. ${ }^{40-45}$ However, GP CL fitting could be improved with different $C L$ fitting software that analyses Placido-based corneal topography curvature data to propose the lens parameters, mainly base optic zone radius and lens diameter. ${ }^{40,41,46-49}$ Using these software could decrease the number of diagnostic lenses necessary to achieve an acceptable CL fit and reduce the chair time in keratoconus patients. ${ }^{10,40,41,46}$

Although, corneal topography is probably the most commonly used tool for the diagnosis of keratoconus, it is accepted that this technique may lead to false negatives in the subclinical phase. That means that Placidobased videokeratographers cannotidentify very mild forms of keratoconus (fruste keratoconus) that would require to be identified, assessing corneal thickness and anterior/posterior curvature measurements over the entire cornea provided with corneal tomography.22.50 Standard corneal topography could be an acceptable technique in primary care but not in speciality clinics or in screening refractive surgical patients, ${ }^{14-16}$ where a complete diagnosis is necessary and complete corneal assessment with corneal tomography.
Figure 3: Anterior and posterior corneal elevation and global pachymetry maps achieved with Galilei corneal tomographer in a keratoconus patient
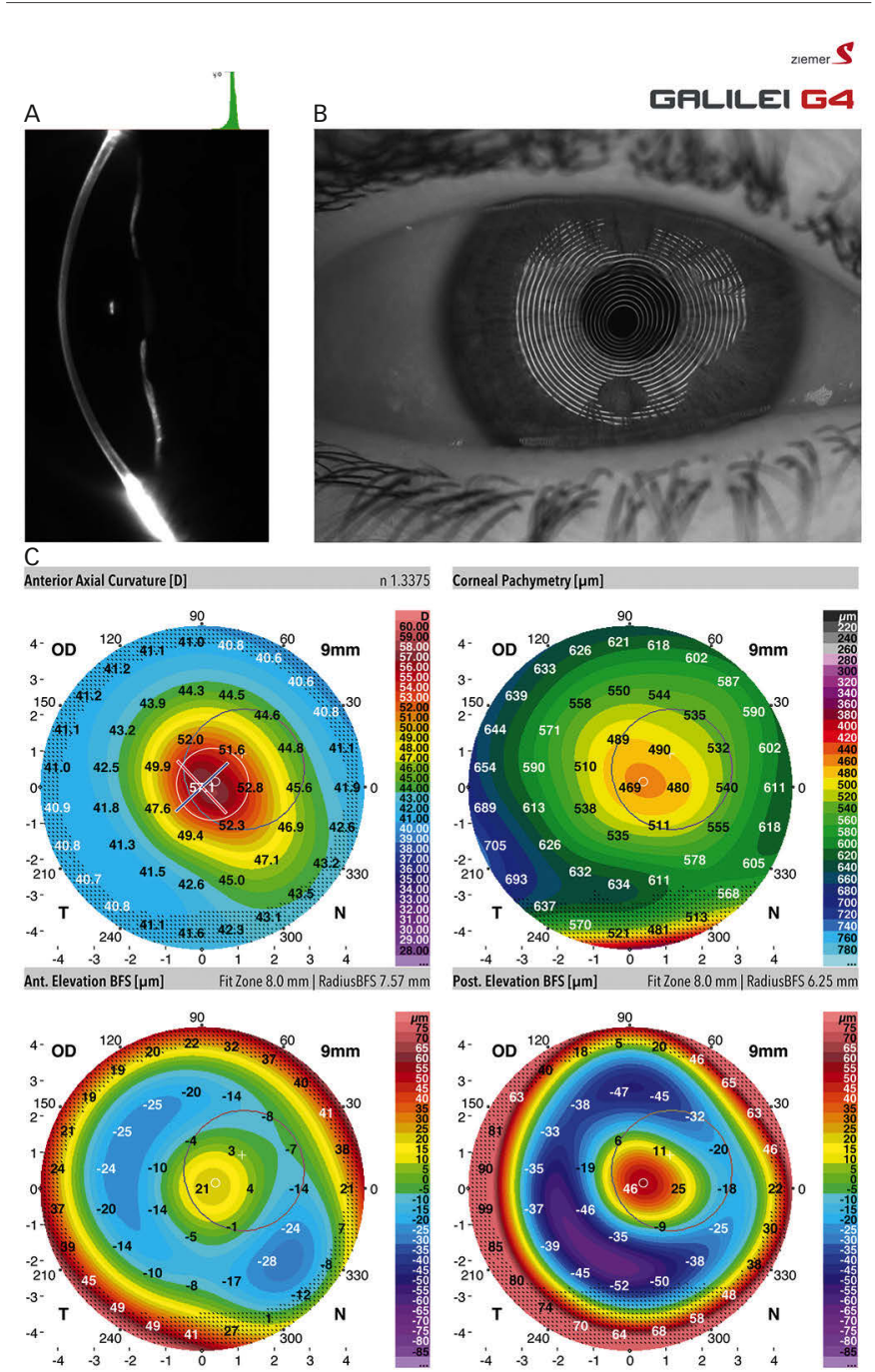

A. Scan image (Scheimpflug image); B. Placido image; C. Axial (power) map, global pachymetry map, anterior and posterior elevation maps.

\section{Corneal tomography}

The term computed tomography is classically used in medicine, for referring to the radiographic technique for imaging a section of an internal solid organ, producing a three-dimensional image. Corneal tomography allows three-dimensional characterisation of the cornea (Figure 2) after anterior and posterior corneal surface analysis, using different slit-imaging technologies, ${ }^{2,51,52}$ such as vertical slit scanning, 53,54 rotational Scheimpflug imaging, ${ }^{55}$ arc scanning with very highfrequency ultrasound, and optical coherence tomography. ${ }^{56}$ The first device that permitted imaging of the anterior and posterior corneal

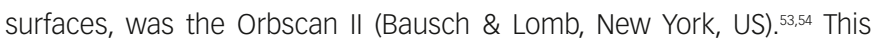
has since been replaced by rotational Scheimpflug devices, such as: Pentacam ${ }^{\circledR}$ (OCULUS Optikgeräte GmbH, Wetzlar, Germany), ${ }^{57}$ WaveLight ${ }^{\circledR}$ OculyzerTm (Alcon, Texas, US)56 and Preciso (Ivis Technologies, Taranto, Italy). Finally, other devices combine Placido-based topography with slit-image analysis and are collectively named hybrid systems, hybrid topographers or dual Scheimpflug-Placido tomographers. Highlight Galilei G4 (Ziemer, Port, Switzerland), ${ }^{58}$ TMS-5 (Tomey, Aichi, Japan) and SIRIUS (CSO, Firenze, Italy) (99 $^{59}$ re examples of these devices. In summary, corneal tomography defines the spatial relationship between the anterior and posterior corneal surfaces and provides a global thickness corneal map (Figure 3). 
Figure 4: Anterior segment optical coherence tomography in a keratoconus patient (OCT-SA-Casia; Tomey, Aichi, Japan)

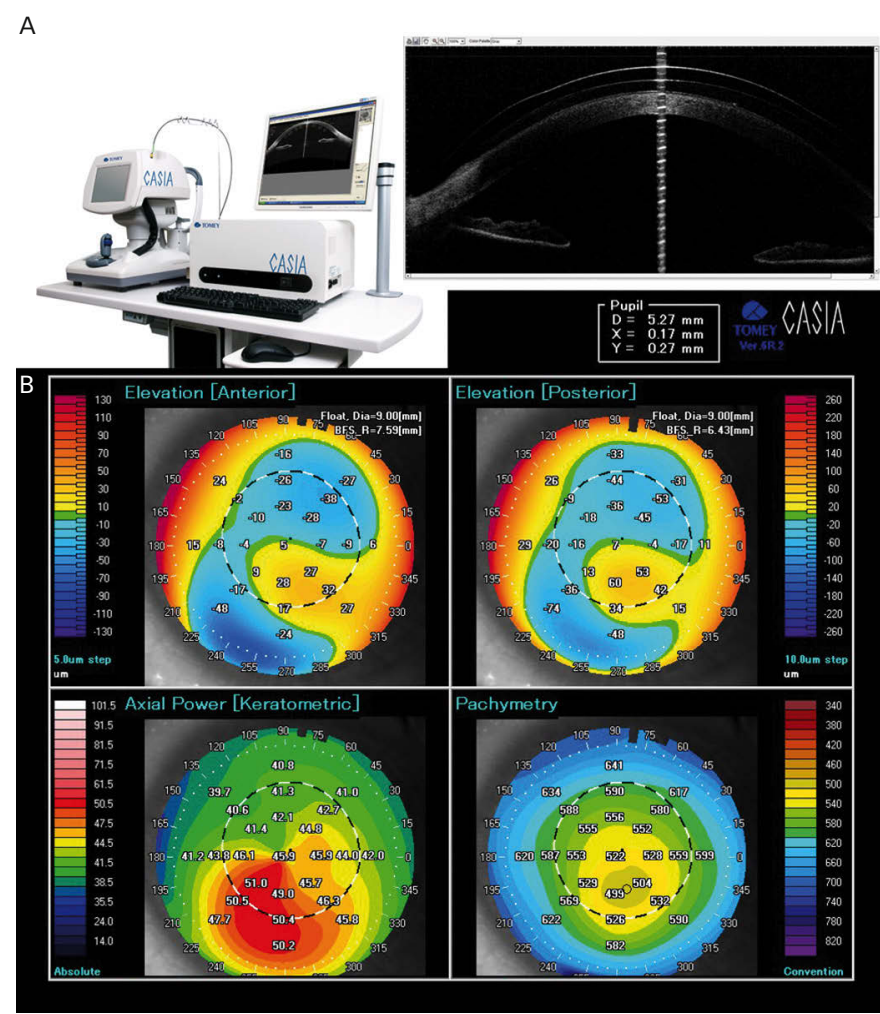

A. Scan image with a scleral lens; B. Anterior and posterior elevation maps, axial (power) map and global pachymetry map.

Corneal tomography has been recognised as a critical diagnostic component in keratoconus patients' assessment, ${ }^{5}$ helping in diagnosis (differentiating between fustre and clinical keratoconus) and monitoring progression, because it is necessary to confirm changes on the posterior corneal surface and corneal thickness alteration in order to diagnose (and monitor) keratoconus. ${ }^{5,13,50,60,61}$

\section{Anterior segment optical coherence tomography}

The first report of AS-OCT imaging appeared in 1994.62 OCT compares the time delay of infrared light $(1310 \mathrm{~nm})$ reflected from the anterior segment structures against a reference reflection, achieving a high resolution cross-sectional image of the anterior segment of the eye (from 2 to $20 \mu \mathrm{m}$ ). ${ }^{63}$

There are three commercial AS-OCT devices; Visante (Carl Zeiss Meditec, Jena, Germany), RTVue-OCT (Optovue, California, US) and Casia SS1000 (Tomey, Aichi, Japan). ${ }^{44,65}$ AS-OCT has been proposed to assess keratoconus patients (Figure 4):66 helping to investigate corneal thickness asymmetry, ${ }^{67}$ epithelial thickness-distribution characteristics ${ }^{68}$ and monitoring progression. ${ }^{19} \mathrm{AS}-\mathrm{OCT}$ could be a promise tool in keratoconus diagnosis (helping to differentiate between fustre and clinical forms of keratoconus of healthy corneas).

\section{Biomechanical devices}

Keratoconus corneas show abnormalities in biomechanical response when they are compared to normal corneas in ex-vivo studies.69,70 However, in-vivo measurement of corneal biomechanics remains a difficult task, and just two commercially available instruments have been proposed; $1,17,72$ the Ocular Response Analyzer ${ }^{\circledR}$ (ORA; Reichert, New York, US) and the Corneal Visualization Scheimpflug Technology (Corvis ${ }^{\circledR}$ ST; Oculus Optikgeräte GmbH, Wetzlar, Germany).
Table 1: Commercially available methods and instruments for corneal assessment

\begin{tabular}{|c|c|c|}
\hline Technology & Method & Product (manufacturer) \\
\hline \multirow[t]{2}{*}{ Keratometry } & Javal-Schiotz principle & Two position keratometer* \\
\hline & Bausch \& Lomb principle & One position keratometer* \\
\hline $\begin{array}{l}\text { Corneal } \\
\text { topography }\end{array}$ & Videokeratoscope & $\begin{array}{l}\text { ATLAS 9000тм (Carl Zeiss Meditec, } \\
\text { Jena, Germany) } \\
\text { Keratograph (OCULUS Optikgeräte } \\
\text { GmbH, Wetzlar, Germany) } \\
\text { CA-800 (Topcon, Tokyo, Japan) } \\
\text { Medmont E300 (Medmont, Victoria, } \\
\text { Australia) } \\
\text { TMS-4a (Tomey, Aichi, Japan) } \\
\text { OPD-Scan III (Nidek Technologies, } \\
\text { Padua, Italy) } \\
\text { EyeSys 2000 (EyeSys Vision Inc, } \\
\text { Texas, US) }\end{array}$ \\
\hline \multirow{5}{*}{$\begin{array}{l}\text { Corneal } \\
\text { tomography }\end{array}$} & Vertical slit-scan & Orbscan II (Bauch\&Lomb, EE.UU.) \\
\hline & Rotating Scheimpflug & $\begin{array}{l}\text { Pentacam }{ }^{\circledR} \text { (OCULUS Optikgeräte } \\
\text { GmbH, Wetzlar, Germany) } \\
\text { WaveLight }^{\circledR} \text { OculyzerTM (Alcon, } \text { Texas, US) } \\
\text { Preciso (Ivis Technologies, Taranto, } \\
\text { Italy) }\end{array}$ \\
\hline & Hybrid system & $\begin{array}{l}\text { Galilei G4 (Ziemer, Port, Switzerland) } \\
\text { TMS-5 (Tomey, Aichi, Japan) } \\
\text { SIRIUS (CSO, Firenze, Italy) }\end{array}$ \\
\hline & $\begin{array}{l}\text { Anterior segment optical } \\
\text { coherence tomography } \\
\text { (AS-OCT) }\end{array}$ & $\begin{array}{l}\text { Visante (Carl Zeiss Meditec, Jena, } \\
\text { Germany) } \\
\text { RTVue-OCT (Optovue, California, US) } \\
\text { Casia SS-1000 (Tomey, Aichi, Japan) }\end{array}$ \\
\hline & $\begin{array}{l}\text { Arc scanning with } \\
\text { very high-frequency } \\
\text { ultrasound }\end{array}$ & Artemis 3 (ArcScan, Colorado, US) \\
\hline \multirow[t]{2}{*}{$\begin{array}{l}\text { Corneal } \\
\text { biomechanical }\end{array}$} & $\begin{array}{l}\text { Bi-directional } \\
\text { applanation process }\end{array}$ & $\begin{array}{l}\text { Ocular Response Analyzer }{ }^{\circledR} \text { (ORA; } \\
\text { Reichert, New York, US) }\end{array}$ \\
\hline & $\begin{array}{l}\text { Ultra-high speed } \\
\text { Scheimpflug camera }\end{array}$ & $\begin{array}{l}\text { Corneal Visualization Scheimpflug } \\
\text { Technology (Corvis }{ }^{\circledR} \text { ST; Oculus } \\
\text { Optikgeräte GmbH, Wetzlar, Germany) }\end{array}$ \\
\hline
\end{tabular}

* Different manufacturers. Non-exhaustive list.

The ORA employs a dynamic bi-directional applanation process with an air-pulse, similar to that of traditional air-puff tonometers. ${ }^{171-73}$ The Corvis ST is a non-contact tonometer with a dual Scheimpflug, high-speed camera that takes more than 4,300 frames per second of the horizontal meridian of the cornea, and captures approximately 140 cross-sectional images of the cornea during the air-puff induced deformation. 1,17,72,74 Both devices determine different corneal biomechanical metrics, mainly corneal hysteresis $(\mathrm{CH})$ and corneal resistance factor (CRF) with ORA -including 37 parameters that describe the waveform of the applanation signal- and deformation amplitude respectively with CorVis. Intraocular pressure (IOP) and IOP value corrected with corneal thickness value is also provided.

Corneal biomechanical metrics are statistically significant between keratoconic and healthy corneas using both ORA ${ }^{71,75-77}$ (keratoconus showed lower $\mathrm{CH}$ and $\mathrm{CRF}$ value) and Corvis ${ }^{71,78-80}$ (keratoconus showed higher deformation amplitude), which could be useful to detect subclinical keratoconus. ${ }^{81}$

Unfortunately, data provide for these devices have not proven to be a definitive keratoconus diagnostic value (able to differentiate between 
keratoconus, forme fruste and normal eyes ${ }^{71}$ because a substantial overlap exists with normal corneas, ${ }^{82,83}$ and further research is necessary to obtain valid cut-off values to use in combination with more clinical data. ${ }^{20,72,75,77,80,84,85}$ In summary, further clinical validation is necessary to inderstand the meaning of these biomechanical parameters obtainied with ORA and Corvis before they can be used in clinical practice. ${ }^{71}$

Other technologies or devices have been proposed to measure corneal biomechanical properties, for example: acoustic radiation force (ARF), ${ }^{86}$ applanation resonance tonometry (ART), ${ }^{87}$ confocal microscopy, ${ }^{88}$ optical coherence elastography, ${ }^{89}$ scanning acoustic microscopy (SAM), ${ }^{90}$ supersonic shear wave imaging $(\mathrm{SSI})^{91}$ that must be validated in human. ${ }^{.1}$

\section{Discussion}

Keratoconus early detection, diagnosis and classification are a challenge. ${ }^{5}$ Both early detection and final diagnosis require a complete eye exam and in-depth corneal assessment using different technologies, such as: corneal topography, corneal tomography, corneal biomechanics and others. However, it is necessary to differentiate between early detection of keratoconus and the final or definitive diagnosis. Early detection is of paramount importance in primary eye care, when a definitive diagnosis is not always required and referral to cornea specialist is necessary to conduct final keratoconus diagnosis. In fact, both procedures are slightly different and should follow different criteria.

Unfortunately, primary eye care service is not easy to define, ${ }^{92}$ but there is a reasonable consensus accepting that primary care is the provision of first contact care for ophthalmic conditions and the follow up, preventive, and rehabilitative care of selected eye conditions, ${ }^{92}$ in contrast with secondary or referral specialist services. ${ }^{93}$ Related with keratoconus screening and diagnosis, in primary eye care, one of the most important purposes should be the detection potential keratoconus indicator (mainly related with patient's corneal shape) in a large population generally asymptomatic or with unspecific symptoms. This practice requires the use of cheap techniques accepted by patients and eye care practitioners with a reasonable sensitivity and specificity. The most commonly used in these clinics are Placido-based corneal topography. In future, if the price of corneal tomographers is reduced, these devices could be introduced in primary eye care clinics. A survey to optometrists in Australia showed that near of $45 \%$ of practitioners have a corneal topographic unit. ${ }^{94}$ This percentage is lower in United Kingdom (26\%) and higher in Spain (60\%) (Author unpublished data).

Primary eye care practitioners play a relevant role in early detection of eye disorders and pathologies. ${ }^{22,95-97}$ Keratoconus could be suspected in risk patients (Down syndrome, relatives of affected patients, ocular allergy, Asian or Arabian ethnicity, eye rubbing, floppy eyelid syndrome, atopy, connective tissue disorders [Marfan syndrome] and others) (5.98,99 $^{5}$ when certain clinical signs are found in the eye exam, such as: scissors reflex during retinoscopy exam, "oil-droplet" reflex (Charleux sign), change in astigmatism refraction (in axe or power) or myopia increase with asymmetry between both eyes. ${ }^{7100-103}$

In opposition, a definitive diagnose is usually done in specialist clinics, for example in cornea units, refractive surgery, etc. This practice requires establish keratoconus presence using the necessary techniques, which may be expensive but justifiable, such as: corneal tomography, AS-OCT and others devices that allow the characterisation of corneal biomechanical properties.

\section{Conclusions}

In summary, corneal topography plays a significant role in keratoconus detection in primary eye care, because anterior Placido-based corneal topographers are cheaper devices with great utility in keratoconus management (fitting GP CL) and follow up. However, a definitive keratoconus diagnosis requires anterior and posterior corneal assessment (with corneal tomography and other techniques) and global pachymetry investigation able to distinguish between healthy cornea, fustre keratoconus and keratoconus. So, corneal tomography is compulsory to conduct a definitive diagnosis or in refractive surgery patients screening.
1. Rio-Cristobal A, Martin R, Corneal assessment technologies: current status, Surv Ophthalmol, 2014;59:599-614.

. Ambrósio R, Belin MW, Imaging of the cornea: topography vs tomography, J Refract Surg, 2010;26:847-9.

3. Feizi S, Yaseri M, Kheiri B, Predictive ability of galilei to distinguish subclinical keratoconus and keratoconus from normal corneas, J Ophthalmic Vis Res, 2016;11:8-16.

4. Zemova E, Eppig T, Seitz B, et al., Interaction between topographic/tomographic parameters and dry eye disease in keratoconus patients, Curr Eye Res, 2014;39:1-8.

5. Gomes JAP, Tan D, Rapuano CJ, et al., Global consensus on keratoconus and ectatic diseases, Cornea, 2015;34:359-69. keratoconus and ectatic diseases, Cornea, 2015,34:359-69. Barnett M, Mannis MJ, Contact lenses in th
keratoconus, Cornea, 2011:30:1510-6.

Rabinowitz YS, Keratoconus, Surv Ophthalmol 1998;42:297-319.

8. Romero-Jiménez M, Santodomingo-Rubido J, Wolffsohn JS, Keratoconus: a review, Cont Lens Anterior Eye, 2010;33:157-66.

9. Ortiz-Toquero $S$, Perez $S$, Rodriguez $G$, et al., The influence of the refractive correction on the vision-related quality of life in keratoconus patients, Qual Life Res, 2016;25:1043-51.

10. Ortiz-Toquero $S$, Martin R, Fitting Gas Permeable Contact Lens in Keratoconus; Still a Challenge?, Ophthalmol Open J. 2016;1:e9-e12.

11. Sanctis $U$ de, Loiacono $C$, Richiardi L, et al., Sensitivity and specificity of posterior corneal elevation measured by Pentacam in discriminating keratoconus/subclinical by Pentacam in discriminating keratoconus/subclic
keratoconus, Ophthalmology, 2008;115:1534-9.

12. Schlegel Z, Hoang-Xuan T, Gatinel D, Comparison of and correlation between anterior and posterior corneal elevation correlation between anterior and posterior corneal elevation
maps in normal eyes and keratoconus-suspect eyes, I Cataract
Refract Surg, 2008:34:789-95.

13. Smadja D, Touboul D, Cohen A, et al., Detection of subclinical keratoconus using an automated decision tree classification Am J Ophthalmol, 2013;156:237-246.e1.

14. Randleman JB, Russell B, Ward MA, et al., Risk factors and prognosis for corneal ectasia after LASIK, Ophthalmology, 2003;110:267-75.

15. Martin R, Rachidi $H$, Stability of posterior corneal elevation one year after myopic laser in situ keratomileusis, Clin Exp Optom, 2012;95:177-86.
16. Santhiago MR, Giacomin NT, Smadja D, Bechara SJ, Ectasia risk factors in refractive surgery, Clin Ophthalmol, 2016;10:713-20

17. Gilani F, Cortese M, Ambrósio RR, et al., Comprehensive anterior segment normal values generated by rotating Scheimpflug tomography, $J$ Cataract Refract Surg, 2013;39:1707-12.

18. Xu Z, Jiang J, Yang C, et al., Value of corneal epithelial and Bowman's layer vertical thickness profiles generated by UHR-OCT for sub-clinical keratoconus diagnosis, SCi Rep 2016;6:31550.

19. Fujimoto H, Maeda N, Shintani A, et al., Quantitative evaluation of the natural progression of keratoconus using threeof the natural progression of keratoconus using three-
dimensional optical coherence tomography, Invest Ophthalmo Vis Sci, 2016;57:169-75.

20. Steinberg J, Katz T, Lücke K, et al., Screening for keratoconus with new dynamic biomechanical in vivo scheimpflug analyses, Cornea, 2015;34:1404-12.

21. Roy AS, Shetty R, Kummelil MK, Keratoconus: a biomechanica perspective on loss of corneal stiffness, Indian I Ophthalmol, 2013;61:392-3.

22. Saad A, Gatinel D, Topographic and tomographic properties of forme fruste keratoconus corneas, Invest Ophthalmol Vis Sci. 2010;51:5546-55.

23. Krumeich JH, Daniel J, Knülle A, Live-epikeratophakia for keratoconus, I Cataract Refract Surg, 1998;24:456-63.

24. McMahon TT, Szczotka-Flynn L, Barr JT, et al., A new method for grading the severity of keratoconus: the Keratoconus Severity grading the severity of keratoconus: the
Score (KSS), Cornea, 2006;25:794-800.

25. Sideroudi H, Labiris $G$, Georgatzoglou $K$, et al., Fourier analysis of videokeratography data: Clinical usefulness in grade I and subclinical keratoconus, J Cataract Refract Surg, 2016;42:731-7. 26. 26. Piñero DP, Nieto JC, Lopez-Miguel A, Characterization of corneal structure in keratoconus, $I$ Cataract Refract Surg, 2012;38:2167-83.

27. Ortiz-Toquero S, Rodriguez G, Juan V de, Martin R, Repeatability of wavefront aberration measurements with a placido-based topographer in normal and keratoconic eyes, $J$ Refract Surg, 2016;32:338-44.

28. Alió JL, Shabayek MH, Corneal higher order aberrations: a method to grade keratoconus, J Refract Surg, 2006;22:539-45.

29. Ortiz-Toquero $S$, Rodriguez $G$, Juan $\vee$ de, Martin R, Repeatability of placido-based corneal topography in keratoconus, Optom Vis Sci, 2014;91:1467-73

30. Cavas-Martínez F, De la Cruz Sánchez E, Nieto Martínez J, et al., Corneal topography in keratoconus: state of the art, Eye and Vision, 2016;3:5

31. Ramos-López D, Martínez-Finkelshtein A, Castro-Luna GM, et al., Screening subclinical keratoconus with placido-based corneal indices, Optom Vis Sci, 2013;90:335-43.

32. Schwiegerling J, Greivenkamp JE, Keratoconus detection based on videokeratoscopic height data, Optom Vis SCi, 1996;73:721-8.

33. Dingeldein SA, Klyce SD, Wilson SE, Quantitative descriptors of corneal shape derived from computer-assisted analysis of photokeratographs, Refract Corneal Surg, 5:372-8.

34. Wilson SE, Klyce SD, Quantitative descriptors of corneal topography. A clinical study, Arch Ophthalmol, 1991;109:349-53. 5. Maeda N, Klyce SD, Smolek MK, Thompson HW, Automated keratoconus screening with corneal topography analysis, Invest Ophthalmol Vis Sci, 1994;35:2749-57.

36. Sedghipour MR, Sadigh AL, Motlagh BF, Revisiting corneal topography for the diagnosis of keratoconus: use of Rabinowitz's KISA\% index, Clin Ophthalmol, 2012;6:181-4.

37. Mahmoud AM, Roberts CJ, Lembach RG, et al., CLMI: the cone location and magnitude index, Cornea, 2008;27:480-7.

38. Dumitrica DM, Colin J, Indices for the detection of keratoconus, Oftalmologia, 2010;54:19-29.

39. Nejabat M, Khalili MR, Dehghani C, Cone location and correction of keratoconus with rigid gas-permeable contact lenses, Cont Lens Anterior Eye, 2012;35:17-21.

40. Nosch DS, Ong GL, Mavrikakis I, Morris J, The application of a computerised videokeratography (CVK) based contact lens fitting software programme on irregularly shaped corneal surfaces, Cont Lens Anterior Eye, 2007;30:239-48.

41. Mandathara PS, Fatima M, Taureen S, et al., RGP contact lens fitting in keratoconus using FITSCAN technology, Cont Lens Anterior Eye, 2013;36:126-9.

42. Pullum $\mathrm{K}$, A keratoconus fitting system using the axial profile to establish optimum lens parameters, Cont Lens Anterior Eye 2003;26:77-84

43. Zhou AJ, Kitamura $\mathrm{K}$, Weissman BA, Contact lens care in keratoconus, Cont Lens Anterior Eye, 2003;26:171-4. 
44. Romero-Jiménez M, Santodomingo-Rubido J, GonzálezMéijome JM, An assessment of the optimal lens fit rate in keratoconus subjects using three-point-touch and apical touch fitting approaches with the rose $\mathrm{K} 2$ lens, Eye contact Lens, 2013:39:269-72.

45. Mandathara Sudharman P, Rathi V, Dumapati S, Rose K lenses for keratoconus--an Indian experience, Eye Contact Lens, 2010;36:220-2.

46. Ortiz-Toquero S, Rodriguez G, Juan V de, Martin R, Rigid Gas Permeable Contact Lens Fitting Using New Software in Keratoconic Eyes, Optom Vis Sci, 2016;93:286-92.

47. Bhatoa NS, Hau S, Ehrlich DP, A comparison of a topographybased rigid gas permeable contact lens design with a conventionally fitted lens in patients with keratoconus, cont Lens Anterior Eye, 2010:33:128-35.

48. Jani BR, Szczotka LB, Efficiency and accuracy of two computerized topography software systems for fitting rigid gas permeable contact lenses, CLAO J, 2000;26:91-6.

49. Siddireddy JS, Mahadevan R, Comparison of conventiona method of contact lens fitting and software based contact lens fitting with Medmont corneal topographer in eyes with corneal scar, Cont Lens Anterior Eye, 2013;36:176-81.

50. Wolf A, Abdallat W, Kollias A, et al., Mild topographic abnormalities that become more suspicious on Scheimpflug imaging, Eur J Ophthalmol, 2009;19:10-7.

51. Konstantopoulos A, Hossain P, Anderson DF, Recent advances in ophthalmic anterior segment imaging: a new era for ophthalmic diagnosis?, Br J Ophthalmol, 2007;91:551-7.

52. Swartz T, Marten L, Wang M, Measuring the cornea: the latest developments in corneal topography, Curr Opin Ophthalmol, 2007;18:325-33

53. Auffarth GU, Wang L, Völcker HE, Keratoconus evaluation using the Orbscan Topography System, I Cataract Refract Surg, 2000;26:222-8.

54. Kampfer T, Wegener A, Dragomirescu V, Hockwin O, Improved biometry of the anterior eye segment, Ophthalmic Res, 1989;21:239-48.

55. Rosales $P$, Marcos S, Pentacam Scheimpflug quantitative imaging of the crystalline lens and intraocular lens, $J$ Refract Surg, 2009;25:421-8.

56. Kanellopoulos AJ, Asimellis G, Comparison of high-resolution scheimpflug and high-frequency ultrasound biomicroscopy to anterior-segment OCT corneal thickness measurements, Clin Ophthalmol, 2013;7:2239-47.

57. Rabsilber TM, Khoramnia R, Auffarth GU, Anterior chamber measurements using Pentacam rotating Scheimpflug camera J Cataract Refract Surg, 2006;32:456-9.

58. Cerviño A, Dominguez-Vicent A, Ferrer-Blasco $\mathrm{T}$, et al , Intrasubject repeatability of corneal power, thickness, and wavefront aberrations with a new version of a dual rotating Scheimpflug-Placido system, I Cataract Refract Surg, Scheimpflug-Placidi:186-92.

59. Montalbán R, Alió JL, Javaloy J, Piñero DP, Intrasubject repeatability in keratoconus-eye measurements obtained with a new Scheimpflug photography-based system, J Cataract Refract Surg, 2013;39:211-8.

60. Muftuoglu O, Ayar O, Ozulken K, et al., Posterior corneal elevation and back difference corneal elevation in diagnosing forme fruste keratoconus in the fellow eyes of unilateral keratoconus patients, I Cataract Refract Surg, 2013;39:1348-57.

61. Smadja D, Santhiago MR, Mello GR, et al., Influence of the reference surface shape for discriminating between normal corneas, subclinical keratoconus, and keratoconus, $J$ Refract surg, 2013:29:274-81.

62. Izatt JA, Hee MR, Swanson EA, et al., Micrometer-scale resolution imaging of the anterior eye in vivo with optical cherence tomography, Arch Ophthalmol, 1994;112:1584-9.

63. Ramos $J$ B, Li Y , Huang D, Clinical and research applications of anterior segment optical coherence tomography - a review, Clin Experiment Ophthalmol, 2009:37:81-9.

64. Wang C, Xia X, Tian B, Zhou S, Comparison of Fourier-Domain and Time-Domain Optical Coherence Tomography in the Measurement of Thinnest Corneal Thickness in Keratoconus, J Ophthalmol, 2015;2015:402925.

65. Szalai E, Berta A, Hassan Z, Módis L, Reliability and repeatability of swept-source Fourier-domain optical coherence tomography and Scheimpflug imaging in keratoconus, I Cataract Refract Surg, 2012;38:485-94.

66. Nakagawa T, Maeda N, Higashiura R, et al., Corneal topographic analysis in patients with keratoconus using 3-dimensional anterior segment optical coherence tomography 1 Cataract Refract Surg, 2011:37:1871-8.

67. Kanellopoulos AJ, Asimellis G, OCT-derived comparison of corneal thickness distribution and asymmetry differences between normal and keratoconic eyes, Cornea, 2014:33:1274-81.

68. Kanellopoulos AJ, Asimellis G, OCT corneal epithelia topographic asymmetry as a sensitive diagnostic tool for early and advancing keratoconus, Clin Ophthalmol, 2014;8:2277-87.

69. 69. Nash IS, Greene PR, Foster CS, Comparison of mechanica properties of keratoconus and normal corneas, Exp Eye Res, 1982;35:413-24.

70. 70. Andreassen $T$, Simonsen $A H$, Oxlund $H$, Biomechanical properties of keratoconus and normal corneas, Exp Eye Res, 1980;31:435-41

71. Bao F, Geraghty B, Wang Q, Elsheikh A, Consideration of corneal biomechanics in the diagnosis and management of keratoconus: is it important? Eye Vis, 2016:3:18

72. Piñero DP, Alcón $N$, In vivo characterization of corneal biomechanics, I Cataract Refract Surg, 2014:40:870-87.

73. Luce DA, Determining in vivo biomechanical properties of the cornea with an ocular response analyser, $J$ Cataract Refract surg, 2005;31:156-62

74. Valbon BF, Ambrósio R, Fontes BM, et al., Ocular biomechanica metrics by CorVis ST in healthy Brazilian patients, $J$ Refract Surg, 2014;30:468-73

75. Shah S, Laiquzzaman M, Bhojwani R, et al., Assessment of the biomechanical properties of the cornea with the ocula response analyzer in normal and keratoconic eyes, Invest Ophthalmol Vis Sci, 2007;48:3026-31.

76. Schweitzer C, Roberts CJ, Mahmoud AM, et al., screening of forme fruste keratoconus with the ocular response analyser, Invest Ophthalmol Vis SCi, 2010:51:2403-10

77. Fontes BM, Ambrósio R, Jardim D, et al., Corneal biomechanica metrics and anterior segment parameters in mild keratoconus, Ophthalmology, 2010;117:673-9.

78. Tian L, Huang Y-F, Wang L-Q, et al., Corneal biomechanica assessment using corneal visualization scheimpflug technology in keratoconic and normal eyes, J Ophthalmol, 2014;2014:147516.

79. Ali NQ, Patel D V, MCGhee CNJ, Biomechanical responses of healthy and keratoconic corneas measured using a noncontact scheimpflug-based tonometer, Invest Ophthalmol Vis Sci, 2014;55:3651-9

80. Tian L, Ko MWL, Wang L, et al., Assessment of ocula biomechanics using dynamic ultra high-speed Scheimpflug imaging in keratoconic and normal eyes, J Refract Surg. 2014;30:785-91.

81. Pniakowska Z, Jurowski P, Detection of the early keratoconus based on corneal biomechanical properties in the refractive surgery candidates, Indian 1 ( phthalmol, 2016:64:109-13.

82. Fontes BM, Ambrósio R, Velarde GC, Nosé W, Ocular response analyzer measurements in keratoconus with normal central corneal thickness compared with matched normal control eyes, I Refract Surg, 2011:27:209-15.

83. Johnson RD Nguyen MT, Lee $\mathrm{N}$, Hamilton DR, Cornea biomechanical properties in normal, forme fruste keratoconus, and manifest keratoconus after statistical correction for potentially confounding factors, Cornea, 2011;30:516-23.

. Kirwan C, OMalley D, O Keefe M, Corneal hysteresis and corneal resistance factor in keratoectasia: findings using the Reichert ocular response analyzer, Ophthalmologica, 2008;222:334-7.

85. Luz A, Lopes B, Hallahan KM, et al., Discriminant Value of Custom Ocular Response Analyzer Waveform Derivatives in Forme Fruste Keratoconus, Am J Ophthalmol, 2016:164:14-21

86. Urs R, Lloyd HO, Silverman RH, Acoustic radiation force for noninvasive evaluation of corneal biomechanical changes induced by cross-linking therapy, J Ultrasound Med, 2014:33:1417-26.

87. Beckman Rehnman J Behndig A, Hallberg P Lindén C. Increased corneal hysteresis after corneal collagen crosslinking: a study based on applanation resonance technology, JAMA ophthalmol, 2014;132:1426-32.

88. Scarcelli G, Besner S, Pineda R, et al., In vivo biomechanical mapping of normal and keratoconus corneas, JAMA Ophthalmol, 2015;133:480-2.

89. Ford MR, Dupps WJ, Rollins AM, et al., Method for optical coherence elastography of the cornea, J Biomed Opt, 16:16005.

90. Beshtawi IM, Akhtar R, Hillarby MC, et al., Biomechanical Changes of Collagen Cross-Linking on Human Keratoconic Corneas Using Scanning Acoustic Microscopy, Curr Eye Res, 2016:41:609-15.

91. Touboul D, Gennisson J-L, Nguyen T-M, et al., Supersonic shear wave elastography for the in vivo evaluation of transepithelia corneal collagen cross-linking, Invest Ophthalmol Vis Sci. corneal collagen

92. Riad SF, Dart JKG, Cooling RJ, Primary care and ophthalmology in the United Kingdom, Br J Ophthalmol, 2003;87:493-9.

93. Starfield B, Is primary care essential?, Lance 1994;344:1129-33.

94. Hodge C, Chan C, Zantos S, et al., Therapeutic treatment of keratoconus: a survey of local optometric practice criteria Clin Exp Optom, 2015;98:312-8.

95. Duenas MR, Public health and optometry--an eye on prevention, J Am Optom Assoc, 1997;68:211-3.

96. Fingeret $\mathrm{M}$, Therapeutics and the profession of optometry-a look back, Optom Vis Sci, 2012:89:372.

97. Kalloniatis M, Ly C, The role of optometry in collaborative eye care, Clin Exp Optom, 2016;99:201-3.

98. McGhee CNJ, 2008 Sir Norman McAlister Gregg Lecture: 150 years of practical observations on the conical cornewhat have we learned? Clin Experiment Ophthalmol 2009;37:160-76

99. Gordon-Shaag A, Millodot M, Shneor E, Liu Y, The genetic and environmental factors for keratoconus, Biomed Res Int, 2015;2015:795738

100. Goebels S, Käsmann-Kellner B, Eppig T, et al., Can retinoscopy keep up in keratoconus diagnosis?, Cont Lens Anterior Eye, 2015;38:234-9.

101. Naderan M, Shoar S, Kamaleddin MA, et al., Keratoconus Clinical Findings According to Different Classifications, Cornea, 2015;34:1005-11.

102. Vazirani J, Basu S, Keratoconus: current perspectives, Clin Ophthalmol, 2013;7:2019-30.

103. Henriquez MA, Izquierdo L, Belin MW, Intereye Asymmetry in Eyes With Keratoconus and High Ammetropia: Scheimpflug Imaging Analysis, Cornea, 2015;34 Suppl 1:S57-60. 